UDC 621.791.14

Author: RIZVANOV Rif Garifovich, Doctor of Engineering, Professor, Ufa State Petroleum Technological University; Kosmonavtov str., 1, Ufa, Russia, 450062;

Author: MULIKOV Denis Shamilevich, Lecturer, Ufa State Petroleum Technological University; Kosmonavtov str., 1, Ufa, Russia, 450062;

Author: KARETNIKOV Denis Vladimirovich, PhD in Engineering, Associate Professor, Ufa State Petroleum Technological University; Kosmonavtov str., 1, Ufa, Russia, 450062;

Author: CHEREPASHKIN Sergej Evgenevich, PhD in Engineering, Associate Professor, Ufa State Petroleum Technological University; Kosmonavtov str., 1, Ufa, Russia, 450062;

Author: SHIRGAZINA Regina Firgatovna, Graduate Student, Ufa State Petroleum Technological University; Kosmonavtov str., 1, Ufa, Russia, 450062

\title{
CORROSION RESISTANCE OF «TUBE - TUBESHEET» WELD JOINT OBTAINED BY FRICTION WELDING
}

\section{EXTENDED ABSTRACT:}

Shell-and-tube heat exchangers are widely applied for implementation of various processes at ventures of fuel and energy complex. Cost of production and reliability of heat exchangers of this type is to a wide extent determined by corresponding characteristics of tube bundle, "tube - tubesheet» is its typical joint in particular when welding operations are used in order to attach tubes to tubesheet in addition to expansion. When manufacturing such equipment of heat-resistant chrome-bearing or chromium-molybdenum steels including steel $15 \mathrm{H} 5 \mathrm{M}$, the process of fixed joint manufacturing gets significantly more complicated and costly due to the necessity to use thermal treatment before, during and after welding (this problem is particularly applicable for manufacturing of large-size equipment). One of the options to exclude thermal treatment from manufacturing process is to use "non-arc» welding methods - laser welding, explosion welding as well as friction welding. Use of each of the welding methods mentioned above during production of heat-exchange equipment has its process challenges and peculiarities.

This article gives a comparative analysis of weld structure and distribution of electrode potentials of welded joints and parent metal of the joints simulating welding of tube to tubesheet of steel $15 \mathrm{H} 5 \mathrm{M}$ using the following welding meth- 
ods: shielded manual arc welding, tungsten-arc inert-gas welding and friction welding.

Comparative analysis of macro- and microstructures of specific zones of the studied welded joints showed that the joints produced by arc welding methods do not exhibit evident inhomogeneity of the structure after application of thermal treatment which is explained by the correctness of thermal treatment. Joints obtained via friction welding are characterized by structural inhomogeneity of the welded joint zone metal microstructure.

The ultra-fine-grained structure obtained as a result of friction welding makes it possible to speak of a qualitative improvement in the structure of compounds as a result of exposure to a metal at the nanolevel.

The conducted study of electrode potential values in specific points of parent metal and of welded joints obtained via different methods showed, that from the electrochemical corrosion point of view the "tube - tubesheet» joints obtained by friction welding without thermal treatment are highly competitive in terms of corrosion resistance with similar details obtained via arc welding methods. This fact allows to consider the friction welding method of "tube - tubesheet» fixed joints manufacturing as an alternative for arc welding methods, which in its turn not only allows producers to obtain «tube - tubesheet» fixed joints with high level of strength and plastic properties without thermal treatment but also significantly reduce energy and labor costs on manufacturing of tube bundles of shell-and-tube heat exchangers, including those made of steel $15 \mathrm{H} 5 \mathrm{M}$.

Key words: Shell-and-tube heat exchangers, «tube - tubesheet» joint, steel $15 \mathrm{H} 5 \mathrm{M}$, energy costs reduction.

MAChine-REAdable information on CC-LiCEnses (HTML-CODE) IN METAdATA OF THE PAPER

$<$ a rel="license" href="http://creativecommons.org/licenses/by/4.0/" $><$ img alt="Creative Commons License" style="borderwidth:0" src="https://i.creativecommons.org/l/by/4.0/88x31.png" / ></a $><$ br $/><$ span xmlns:dct="http://purl. org/dc/terms/" href="http://purl.org/dc/dcmitype/Text" property="dct:title" rel="dct:type" $>$ Corrosion resistance of "tube - tubesheet» weld joint obtained by friction welding. </span $>$ by $<$ a xmlns:cc="http://creativecommons.org/ ns\#" href="Nanotehnologii v stroitel'stve = Nanotechnologies in Construction. 2017, Vol. 9, no. 4, pp. 97-115. DOI: dx.doi.org/10.15828/2075-8545-2017-9-4-97-115. (In Russian). " property="cc:attributionName" rel="cc:attribution URL">Rizvanov R.G., Mulikov D.Sh., Karetnikov D.V., Cherepashkin S.E., Shirgazina R.F. $</ a>$ is licensed under a $<$ a rel="license" href="http://creativecommons.org/licenses/by/4.0/" $>$ Creative Commons Attribution 4.0 International License $</$ a $>$. $<$ br / $>$ Based on a work at $<$ a xmlns:dct="http://purl.org/dc/terms/" href=" http://nanobuild.ru/en_EN/ nanobuild-4-2017/" rel="dct:source" > http://nanobuild.ru/en_EN/nanobuild-4-2017/</a >.<br />Permissions beyond the scope of this license may be available at $<$ a xmlns:cc="http://creativecommons.org/ns\#" href="ufa.savjulia@gmail.com" rel="cc:morePermissions" $>$ ufa.savjulia@gmail.com $</ \mathrm{a}>$. 


\section{References:}

1. Mulikov D.Sh., Rizvanov R.G., Karetnikov D.V., Fayrushin A.M. Ocenka vozmozhnosti primenenija svarki treniem dlja izgotovlenija teploobmennogo oborudovanija iz stali $15 \mathrm{H} 5 \mathrm{M}$ [Evaluation of friction welding application for manufacturing of heat-exchange equipment of steel $15 \mathrm{H} 5 \mathrm{M}$ ]. Svarochnoe proizvodstvo [Welding industry]. 2016, No.3, pp. 47-51. (In Russian).

2. Karetnikov D.V., Rizvanov R.G., Mulikov D.Sh., Balandina A.G., Fayrushin A.M. Pat. 2524468 Russian Federation, IPC51 V 23 K 20/12, V 23 K 31/02. A method to obtain «tube - tubesheet» joint by friction welding/ applicant and patent owner Ufa.UGNTU. - 2012149757/02; appl. 21.11.2012; publ. 27.07.2014, Bull. No. 21, 6 p. (In Russian).

3. Rizvanov R.G., Karetnikov D.V., Fayrushin A.M., Mulikov D.Sh. O vozmozhnosti primenenija svarki treniem dlja izgotovlenija svarnyh trubnyh puchkov iz stali 15H5M [On possibility of friction welding application for manufacturing welded tube bundles of steel $15 \mathrm{H} 5 \mathrm{M}]$. Doneckij nacional'nyj tehnicheskij universitet «Progressivnye tehnologii i sistemy mashinostroenija» [Advanced mechanical engineering technologies and systems]. 2014, No. 4 (50), pp. 168-173. (In Russian).

4. Tkatchenko G.P., Brif V.M. Izgotovlenie i remont kozhuhotrubchatoj teploobmennoj apparatury [Manufacturing and repair of shell-and-tube heat-exchange equipment]. Moscow, Mashinostroenie, 1980, 160 p. (In Russian).

5. Tukaev R.F., Ibragimov I.G., Fairushin A.M., Sisanbaev A.V. Sravnitel'nyj analiz svarnyh shvov v uzle «truba - trubnaja reshetka» kozhuhotrubchatogo teploobmennogo apparata iz zharoprochnoj stali $15 \mathrm{H} 5 \mathrm{M}$, poluchennyh razlichnymi sposobami svarki [Weld seams comparative analysis in «tube - tubesheet» joint of a shell-and-tube heat-exchanger made of heat-resistant steel $15 \mathrm{H} 5 \mathrm{M}$ obtained by different welding methods]. Neftegazovoe delo [Oil and gas engineering]. 2013, No. 5, pp. 363-375. (In Russian).

6. Halimov A.A., Zharinova N.V., Halimov A.G., Fayrushin A.M. Obespechenie tehnologicheskoj prochnosti svarnyh soedinenij iz martensitnyh hromistyh stalej tipa 15H5M [Process strength implementation for weld joints made of martensitic chromium steels such as $15 \mathrm{H} 5 \mathrm{M}$ ]. Neftegazovoe delo [Oil and gas engineering]. 2012, No. 3, pp. 102-108. (In Russian).

7. Tcherepashkin S.E., Latypov O.R., Kravtsov V.V. Metody korrozionnyh issledovanij: ucheb. posobie. [Corrosion research methods: handbook]. Ufa, RIC USPTU, 2014, 86 p. (In Russian).

8. Salakhov T.R., Yamaliev V.U., Dubinsky V. A field-proven methodology for realtime drill bit condition assessment and drilling performance optimization [A field- 
proven methodology for real-time drill bit condition assessment and drilling performance optimization]. In Proc. of SPE Russian Oil and Gas Technical Conference and Exhibition. 2008, pp. 281-288. (In Russian).

9. Yamilev M.Z., Ibragimov I.G., Fayrushin A.M., Salmin A.N. Sovershenstvovanie tehnologii vypolnenija svarnogo uzla «truba - trubnaja reshetka» kozhuhotrubchatyh teploobmennyh apparatov, izgotovlennyh iz martensitnyh stalej [ «Tube tubesheet» weld joint manufacturing technology update for shell-and-tube heat exchangers made of martensitic chromium steels]. Neftegazovoe delo [Oil and gas engineering]. 2009, No. 1, pp. 194-197. (In Russian).

10. Yamilev M.Z. Sovershenstvovanie tehnologii izgotovlenija uzla «truba - trubnaja reshetka» kozhuhotrubchatogo teploobmennogo apparata iz zharoprochnoj stali 15H5M: diss.... kand. tehn. Nauk [«Tube - tubesheet» weld joint manufacturing technology update for shell-and-tube heat exchanger made of heat-resistant steel 15H5M: PhD thesis]. Ufa, 2011, 108 p. (In Russian).

11. Halimov A.G, Bakiyev A.V. Razrabotka tehnologii mehanizirovannoj svarki v srede zashhitnyh gazov stalej tipa 15H5M [Development of machine welding technologies for heat-resistant steels such as $15 \mathrm{H} 5 \mathrm{M}]$. Proc. of conference RIC USPTU. 1998, pp. 51-52. (In Russian).

12. Lashchinskii A.A., Tolchinskii A.R. Osnovy konstruirovanija i rascheta himicheskoj apparatury: spravochnik [Basics of designing and calculating chemical equipment: a reference book]. Moscow, Alliance, 2008, 752 p. (In Russian).

13. Zainullin R.S. Resursosberegajushhie tehnologii $\mathrm{v}$ neftehimicheskom apparatostroenii [Resource-saving technologies in petrochemical apparatus building]. Ufa, TRANSTEK, 2000, 348 p. (In Russian).

14. Khalimov A.G., Zainullin R.S., Khalimov A.A. Tehnicheskaja diagnostika i ocenka resursa apparatov [Technical diagnostics and resource evaluation of equipment]. Ufa, USPTU, 2001, 408 p. (In Russian).

15. Bakiev A.V. Tehnologija apparatostroenija [Technology of Apparatus Engineering]. Ufa: USPTU, 1995, 297 p. (In Russian).

16. Tukaev R.F., Fairushin A.M., Sisanbaev A.V., Kuchukov T.M. Sovershenstvovanie tehnologii izgotovlenija uzla «truba-trubnaja reshetka» kozhuhotrubchatogo teploobmennogo apparata iz stali $15 \mathrm{H} 5 \mathrm{M}$ primeneniem lazernoj svarki [Improvement of the technology for manufacturing "tube - tubesheet» of a shell-and-tube heat exchanger made of 15H5M steel using laser welding]. Proc. of SPbSPU, 2013, № 3, pp. 1179-1185. (In Russian).

17. Mulikov D.Sh., Karetnikov D.V., Rizvanov R.G., Fairushin A.M. Modernizacija konstrukcii uzla kreplenija trub k trubnym reshetkam kozhuhotrubchatyh teploobmennyh apparatov iz stali 15H5M [Modernization of the construction of tube-to-tubesheet assembly of shell-and-tube heat exchangers made of $15 \mathrm{H} 5 \mathrm{M}$ 
steel]. Neftegazovoe delo [Oil and gas industry], 2015, №5, pp. 398-410. (In Russian).

18. Berliner Yu. I., Brif V.M. Analiz primenimosti sovremennyh metodov kreplenija trub k trubnym reshetkam [Analysis of the applicability of modern methods of fastening tubes to tubesheets]. Vysokoproizvoditel'nye metody svarki v him. i neft. mashinostroenii [High-performance welding methods in chemical and petroleum engineering], 1970, № 3, pp. 3-12. (In Russian).

19. Korol'kov P.M., Khanapetov M.V. Sovremennye metody termicheskoj obrabotki svarnyh soedinenij [Modern methods of heat treatment of welded joints]. Moscow, Vysshaya shkola [Higher school], 1987, 112 p. (In Russian)

20. Vill' V.I. Svarka metallov treniem [Welding of metals by friction]. Moscow, Mashinostroenie [Mechanical engineering], 1970, 176 p. (In Russian).

21. Lukin V.I., Koval'chuk V.G., Samorukov M.L., Gridnev Yu.M., Zhegina I.P. Issledovanie vlijanija parametrov svarki treniem i termicheskoj obrabotki na kachestvo svarnyh soedinenij zharoprochnyh deformiruemyh nikelevyh splavov [Investigation of the influence of friction welding parameters and heat treatment on the quality of welded joints of heat-resistant deformable nickel alloys]. Svarochnoe proizvodstvo [Welding industry], 2011, № 4, pp. 26-30. (In Russian).

22. Khalimov A.A., Zharinova N.V., Khalimov A.G., Fairushin A.M. Obespechenie tehnologicheskoj prochnosti svarnyh soedinenij iz martensitnyh hromistyh stalej tipa 15H5M [Provision of technological strength of welded joints of martensitic chromium steels such as $15 \mathrm{H} 5 \mathrm{M}$ ]. Neftegazovoe delo [Oil and gas industry], 2012, №3, pp. 102-108. (In Russian).

23. Ivanov L.A., Muminova S.R. Nanotechnologies and nanomaterials: review of inventions. Part 1 // Nanotehnologii v stroitel'stve = Nanotechnologies in Construction. 2017, Vol. 9, no. 1, pp. 88-106. DOI: dx.doi.org/10.15828/2075-85452017-9-1-88-106. (In Russian).

24. Ivanov L.A., Muminova S.R. New technical solutions in nanotechnology. Part 1. Nanotehnologii v stroitel'stve $=$ Nanotechnologies in Construction. 2016, Vol. 8, no. 2, pp. 52-70. DOI: dx.doi.org/10.15828/2075-8545-2016-8-2-52-70. (In Russian).

\section{DeAr Colleagues!}

THE REFERENCE TO THIS PAPER HAS THE FOLLOWING CITATION FORMAT:

Rizvanov R.G., Mulikov D.Sh., Karetnikov D.V., Cherepashkin S.E., Shirgazina R.F. Corrosion resistance of «tube - tubesheet» weld joint obtained by friction welding. Nanotehnologii v stroitel'stve $=$ Nanotechnologies in Construction. 2017, Vol. 9, no. 4, pp. 97-115. DOI: dx.doi.org/10.15828/2075-8545-2017-94-97-115. (In Russian). 
Автор: РИЗВАНОВ Риф Гарифович, д-р техн. наук, проф., Федеральное государственное бюджетное образовательное учреждение высшего образования Уфимский государственный нефтяной технический университет; ул. Космонавтов, 1, г. Уфа, Россия, 450062;

Автор: МУЛикоВ Денис Шамильевич, преподаватель, Федеральное государственное бюджетное образовательное учреждение высшего образования Уфимский государственный нефтяной технический университет; ул. Космонавтов, 1, г. Уфа, Россия, 450062;

Автор: КАРЕТНИКОВ Денис Владимирович, канд. техн. наук, доц., Федеральное государственное бюджетное образовательное учреждение высшего образования Уфимский государственный нефтяной технический университет; ул. Космонавтов, 1, г. Уфа, Россия, 450062;

Автор: ЧЕРЕПАШКИН Сергей Евгеньевич, канд. техн. наук, доцент, Федеральное государственное бюджетное образовательное учреждение высшего образования Уфимский государственный нефтяной технический университет; ул. Космонавтов, 1, г. Уфа, Россия, 450062;

Автор: ШИРГАЗИНА Регина Фиргатовна, магистрант, Федеральное государственное бюджетное образовательное учреждение высшего образования Уфимский государственный нефтяной технический университет; ул. Космонавтов, 1, г. Уфа, Россия, 450062

\section{КОРРОЗИОННАЯ СТОЙКОСТЬ СВАРНОГО СОЕДИНЕНИЯ УЗЛА «ТРУБА - ТРУБНАЯ РЕШЕТКА», ПОЛУЧЕННОГО СВАРКОЙ ТРЕНИЕМ}

\section{АННОТАЦИЯ К СТАТЬЕ (АВТОРСКОЕ РЕЗЮMе, РЕФЕРАT):}

Кожухотрубные теплообменники широко применяются для реализации различных процессов на предприятиях топливно-энергетического комплекса. Стоимость производства и надежность теплообменников этого типа в значительной степени определяется соответствующими характеристиками трубного пучка, узел «труба - трубная решетка» является его характерным соединением, в частности, при использовании сварочных операций для присоединения труб к трубной решетке в дополнение к развальцовке. При изготовлении такого оборудования из жаропрочных хромистых или хромомолибденовых сталей, в том числе из стали $15 \mathrm{X} 5 \mathrm{M}$, процесс производства неразъемных соединений становится значительно более сложным и дорогостоящим из-за необходимости применения термической обработки до, во время и после сварки (эта проблема особенно применима при изготовлении крупногабаритного оборудования). Одним из вариантов исключения термической обработки из технологического процесса является использование 
«недуговых» способов сварки - лазерной сварки, сварки взрывом, а также сварки трением. Использование каждого из методов сварки, упомянутых выше, во время производства теплообменного оборудования имеет свои технологические проблемы и особенности.

В данной статье приводится сравнительный анализ структуры сварного шва и распределения электродных потенциалов сварных соединений и основного металла швов, имитирующих соединение трубы с трубной решеткой из стали 15Х5М с использованием следующих методов сварки: ручная дуговая сварка металлическим покрытым электродом, дуговая сварка вольфрамовым электродом в среде инертного газа и сварка трением.

Сравнительный анализ макро- и микроструктур определенных зон исследуемых сварных соединений показал, что соединения, полученные методами дуговой сварки, не проявляют явной неоднородности структуры после проведения термической обработки, что объясняется правильностью применения термообработки. Соединения, полученные сваркой трением, характеризуются структурной неоднородностью микроструктуры металла зоны сварного соединения.

Полученная в результате сварки трением ультрамелкозернистая структура позволяет говорить о качественном улучшении структуры соединения в результате воздействия на металл на наноуровне.

Проведенное исследование значений электродного потенциала в конкретных точках основного металла и сварных соединений, полученных различными методами, показало, что с точки зрения электрохимической коррозии соединения «труба - трубная решетка», полученные сваркой трением без термической обработки, являются весьма конкурентоспособными с точки зрения коррозионной стойкости с аналогичными деталями, полученными методами дуговой сварки. Этот факт позволяет рассматривать метод сварки трением узла «труба - трубная решетка» как альтернативу методам дуговой сварки, что, в свою очередь, позволяет не только получить узел «труба трубная решетка" с высоким уровнем прочности и пластических свойств без термической обработки, но также значительно снизить энергетические и трудовые затраты на изготовление трубных пучков кожухотрубных теплообменников, в том числе из стали 15X5M.

Ключевые слова: кожухотрубные теплообменники, соединение «труба трубная решетка», сталь $15 \mathrm{X} 5 \mathrm{M}$, снижение энергозатрат. 
МАШИНОЧИТАЕМАЯ ИНФОРМАЦИЯ О CC-ЛИЦЕНЗИИ В МЕТАДАННЫХ СТАТЬИ (HTML-КОД):

$<$ a rel="license" href="http://creativecommons.org/licenses/by/4.0/"><img alt="Лицензия Creative Commons" style="borderwidth:0" src="https://i.creativecommons.org/l/by/4.0/88x31.png" / ></a $><$ br / Произведение «<span xmlns:dct="http:// purl.org/dc/terms/" href="http://purl.org/dc/dcmitype/Text" property="dct:title" rel="dct:type">Коррозионная стойкость сварного соединения узла «труба - трубная решетка», полученного сваркой трением </span>» созданное автором по имени $<$ a xmlns:cc="http://creativecommons.org/ns\#" href="Нанотехнологии в строительстве. -2017 . - Том 9, № 4. - С. 97-115. - DOI: dx.doi.org/10.15828/2075-8545-2017-9-4-97-115." property="cc:attributionName" rel="cc:attributionURL"> Ризвано в Р.Г., Муликов Д.Ш., Каретников Д.В., Черепашкин С.Е., Ширгазина Р.Ф. </a $>$, публикуется на условиях $<$ a rel="license" href="http://creativecommons.org/licenses/by/4.0/"> лицензии Creative Commons «Attribution» ( ААтрибуция») 4.0 Всемирная $</ \mathrm{a}>$. $<$ br /> Основано на произведении с $<$ a xmlns:dct="http://purl.org/dc/terms/" href="http://nanobuild.ru/ru_RU/ nanobuild-4-2017/" rel="dct:source">http://nanobuild.ru/ru_RU/nanobuild-4-2017/</a>.<br />Разрешения, выходящие за рамки данной лицензии, могут быть доступны на странице $<$ a xmlns:cc="http://creativecommons.org/ns\#" href="ufa. savjulia@gmail.com"rel="cc:morePermissions">ufa.savjulia@gmail.com</a>.

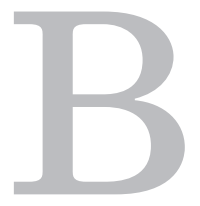

химической, нефтехимической и нефтеперерабатывающей отраслях промышленности, в условиях высоких температур и окислительных серосодержащих сред, нередко применяется оборудование, изготовленное из жаропрочных хромистых и хромомолибденовых сталей $[12,13]$. Среди прочих марок широкое применение для изготовления печного и теплообменного оборудования находят стали марки 15X5M, 12MХ и т.д. Ежегодно, в пакете заказов, по данным различных заводов-изготовителей подобного оборудования, доля данного вида оборудования достигает 20\% [15].

Особенностью получения сварного соединения «труба - трубная решетка» при изготовлении трубного пучка из стали 15Х5М является необходимость предварительного подогрева каждого узла, сопутствующего подогрева, исключающего охлаждение ниже $300^{\circ} \mathrm{C}$, а также проведение высокотемпературного отпуска (равномерный нагрев всего аппарата до температуры $750 . .760^{\circ} \mathrm{C}$, выдержка при этой температуре и последующее медленное охлаждение) $[11,14]$. Все эти операции с целью уменьшения вероятности развития значительных внутренних напряжений и деформаций необходимо вести со скоростями, не превышающими $70 . .100^{\circ} \mathrm{C} /$ час, что не только приводит к усложнению технологического процесса изготовления аппарата, но и его удорожанию. Необходимо отметить, что до проведения термической обработки изделие после сварки не рекомендуется подвергать механическим нагрузкам и транспортировать, а непосредственно отпуск необходимо проводить 
незамедлительно после сварки $[6,9,10]$. Очевидно, что вышеуказанные меры по обеспечению существующего технологического процесса изготовления теплообменного оборудования являются трудоемкими и энергоемкими, а сам процесс изготовления оборудования по данной технологии многократно возрастает [19, 22].

Применение современных технологий, в том числе в области аппаратостроения, позволяет достичь значительных экономических и технологических результатов [23, 24]. На текущий момент разрабатывается несколько альтернативных технологий сварки узла «труба - трубная решетка» из жаропрочных мартенситных сталей типа $15 \mathrm{X} 5 \mathrm{M}$, при которых за счет исключения предварительного, сопутствующего подогревов и послесварочной термообработки снижаются трудоемкость и энергозатраты при изготовлении теплообменного оборудования $[1,3,5,8$, 16-18].

Одним из предлагаемых способов является сварка трением с применением дополнительной ввариваемой втулки $[2,3]$. Вследствие технологической особенности данного способа сварки [20, 21] в конструкции узла проведена модернизация в части изменения конструктивного исполнения трубной решетки. На рис. 1 показана фотография разреза экспериментально сваренного узла, имитирующего приварку трубы к трубной решетке (сварка проводилась на машине для сварки трением ПСТ-20Т, производства ОАО «КТИАМ» г. Челябинск). Для упрощения

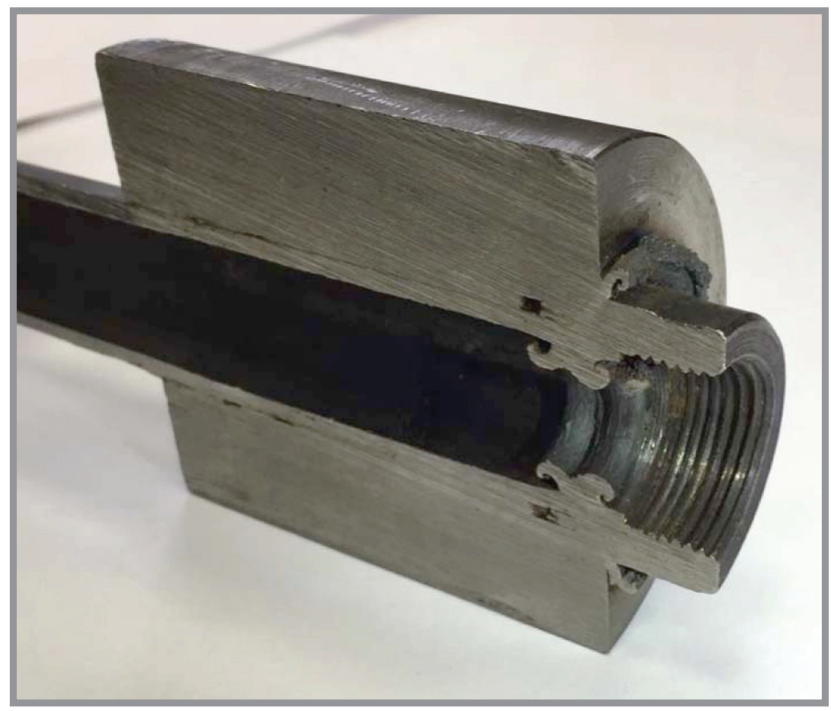

Рис. 1. Фотография экспериментального образца в разрезе 
экспериментов исследования проводились на сварных узлах «труба эквивалентная втулка», в которых втулка моделирует трубную решетку. Диаметр эквивалентной втулки определялся согласно [4].

Учитывая требования к коррозионной стойкости при эксплуатации теплообменного оборудования, изготовленного из жаропрочных мартенситных сталей, были проведены микроструктурные и коррозионные исследования по оценке характеристик узла «труба - трубная решетка», полученного сваркой трением без применения термической обработки в сравнении с образцами, изготовленными дуговой сваркой по существующей технологии с применением термических операций.

Образцы для исследования микроструктуры подготавливали по методике, изложенной в ГОСТ 5639-82. Исследования микроструктуры проводились на оптическом микроскопе с различным увеличением. На рис. 2-5 приведены фотографии микроструктуры металла трубной решетки, металла труб, сварного шва и ввариваемого металла при использовании различных способов сварки.

На рис. 2 представлена макро- и микроструктура образца, сварное соединение которого выполнено сваркой неплавящимся электродом в среде защитных газов (аргона) с применением термических операций (сопутствующего подогрева и высокотемпературного отпуска после сварки). Микроструктура основного металла трубной решетки представляет собой феррит с формой зерен, близкой к равноосной, и карбиды, распределенные неравномерно по границам и телу ферритных зерен. Микроструктура металла трубы представляет собой более вытянутые в направлении прокатки зерна феррита и карбиды, распределенные неравномерно по границам и телу ферритных зерен. Микроструктура металла сварного шва представляет собой вытянутую в направлении кристаллизации структуру, состоящую из феррита и карбидов, распределенных неравномерно по границам и телу ферритных зерен. Зона термического влияния отсутствует, что связано с термической обработкой соединения непосредственно после операции сварки.

На рис. 3 представлена макро- и микроструктура образца, сварное соединение которого выполнено ручной дуговой сваркой покрытыми электродами так же с применением термических операций. Микроструктура основного металла трубной решетки представляет собой феррит с формой зерен, близкой к равноосной, и карбиды, распределенные неравномерно по границам и телу ферритных зерен. 

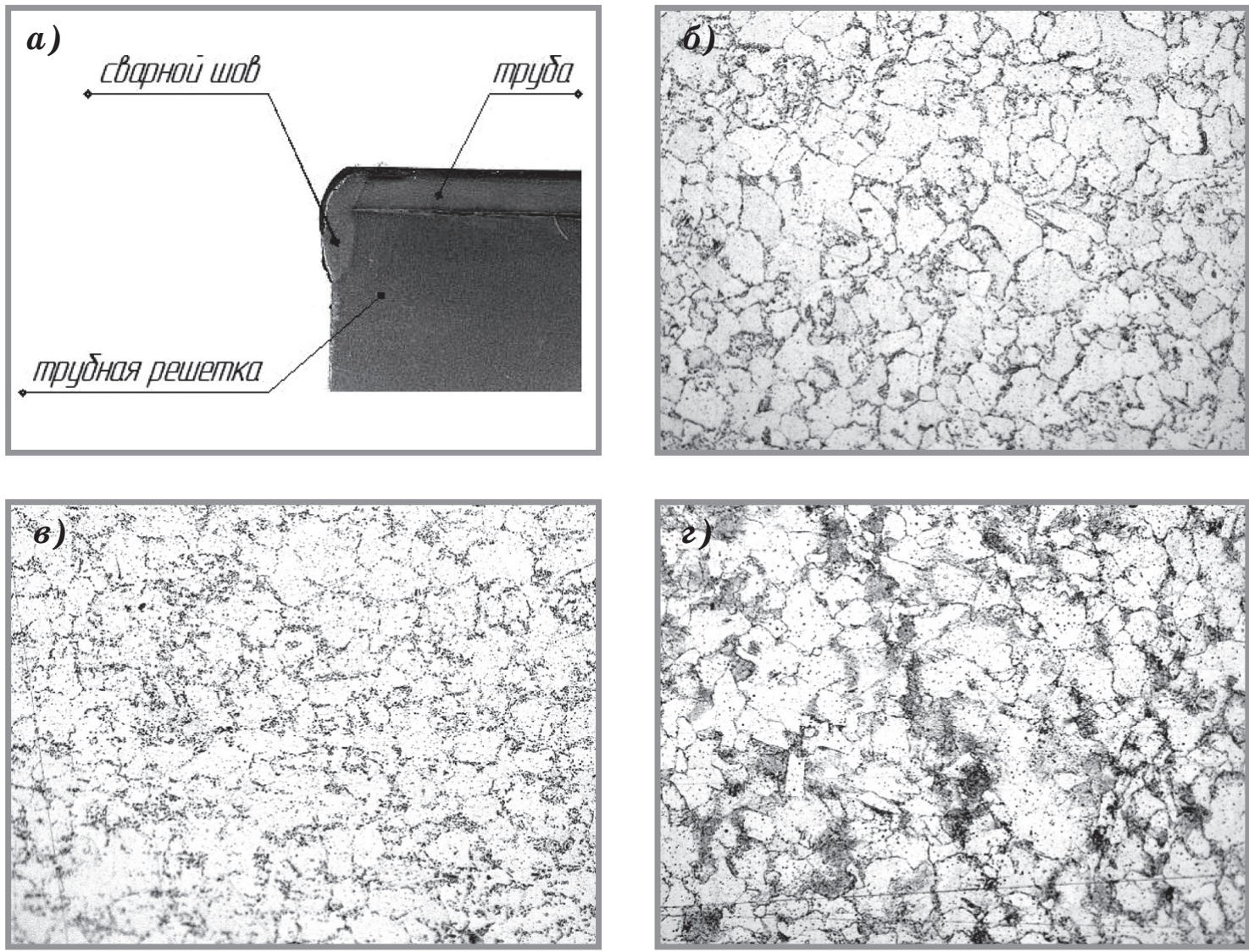

Puc. 2. Микроструктура образца, полученного сваркой неплавящимся электродом в среде защитных газов: а - макроструктура сварного соединения; б - микроструктура металла трубной решетки (х 500); в - микроструктура металла трубы (х 500); г - микроструктура металла сварного шва (х 500)

Микроструктура металла трубы представляет собой более вытянутые в направлении прокатки зерна феррита и карбиды, распределенные равномерно по границам и телу ферритных зерен. Микроструктура металла сварного шва представляет собой вытянутую в направлении кристаллизации структуру, состоящую из феррита и карбидов, распределенных равномерно по телу ферритных зерен. Зона термического влияния также отсутствует.

Отметим, что разница в микроструктуре образцов из втулок, сваренных дуговыми способами, практически отсутствует. Этот факт объясняется проведением в обоих случаях одинаковых по типу и режиму нагрева термических операций. Какому способу отдать предпочтение, в данном случае определяется условиями производства. 

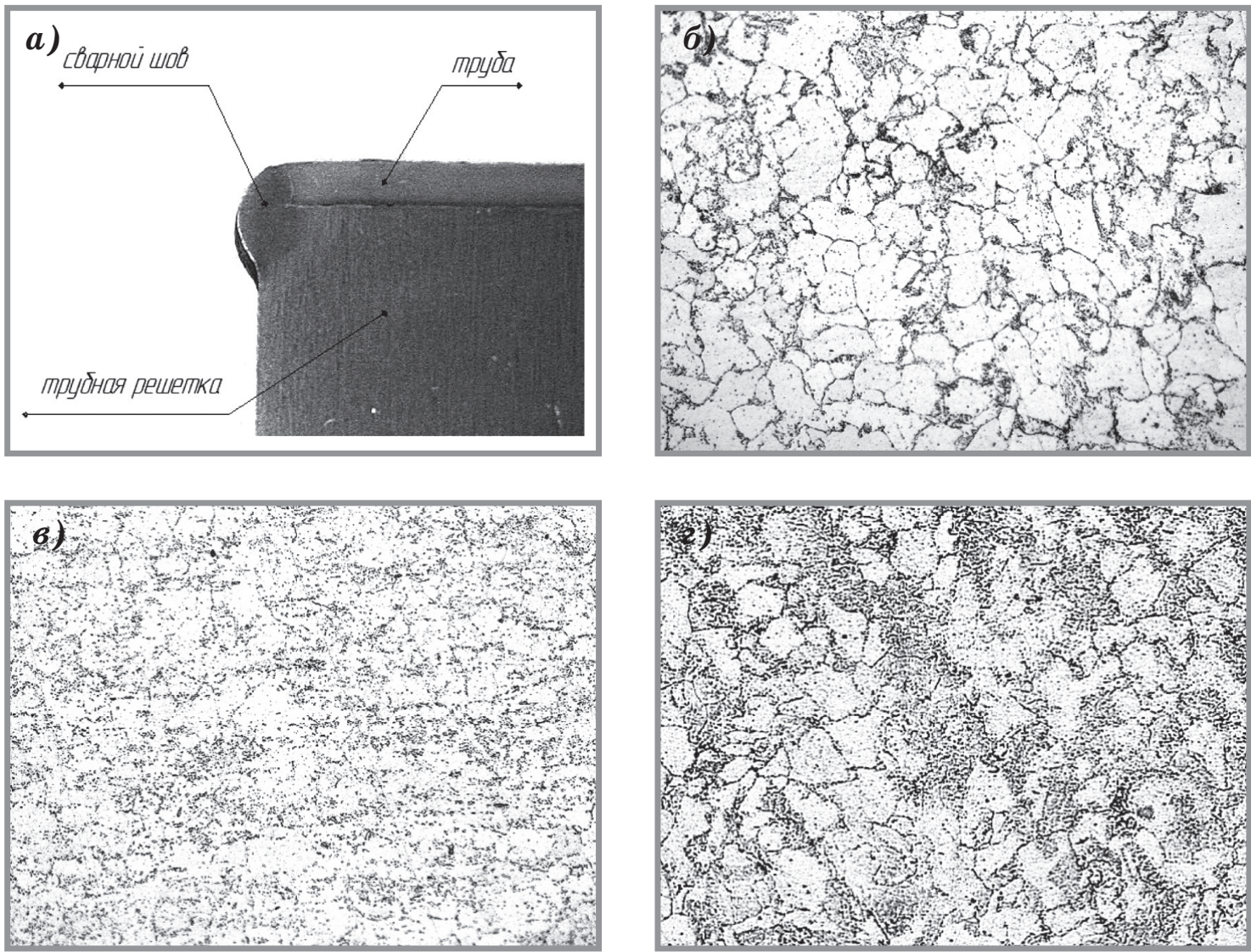

Рис. 3. Микроструктура образца, полученного РАД:

а - макроструктура сварного соединения РАД; б - микроструктура металла трубной решетки (х 500); в - микроструктура металла трубы (х 500);

г - микроструктура металла сварного шва (х 500)

Образец, полученный сваркой трением, отличается как по макро(рис. 4) так и по микроструктуре (рис. 5). Отличительные особенности:

- микроструктура основного металла трубной решетки представляет собой отпущенный бейнит;

- микроструктура металла трубы представляет собой вытянутые в направлении прокатки зерна феррита и карбиды, распределенные равномерно по границам и телу ферритных зерен;

- микроструктура металла ввариваемой детали представляет собой сорбитообразную структуру, состоящую из феррита и карбидов, расположенных равномерно по границам и телу ферритных зерен;

- микроструктура металла сварного шва представляет собой крупноигольчатый мартенсит; 


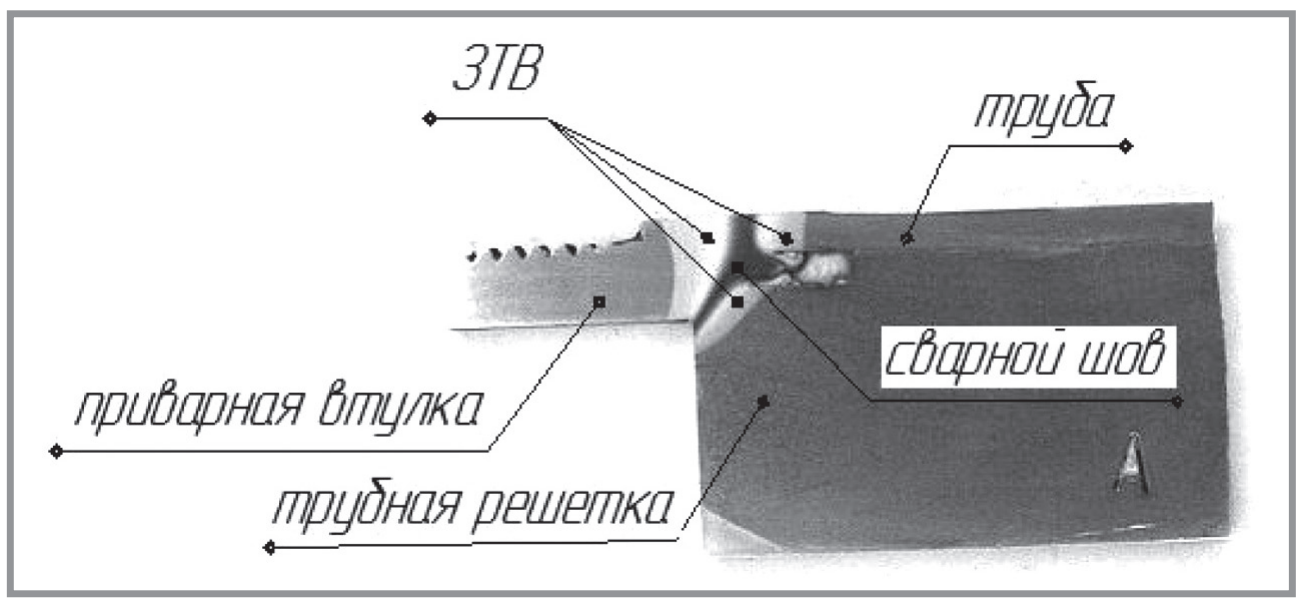

Рис. 4. Макроструктура соединения, полученного сваркой трением
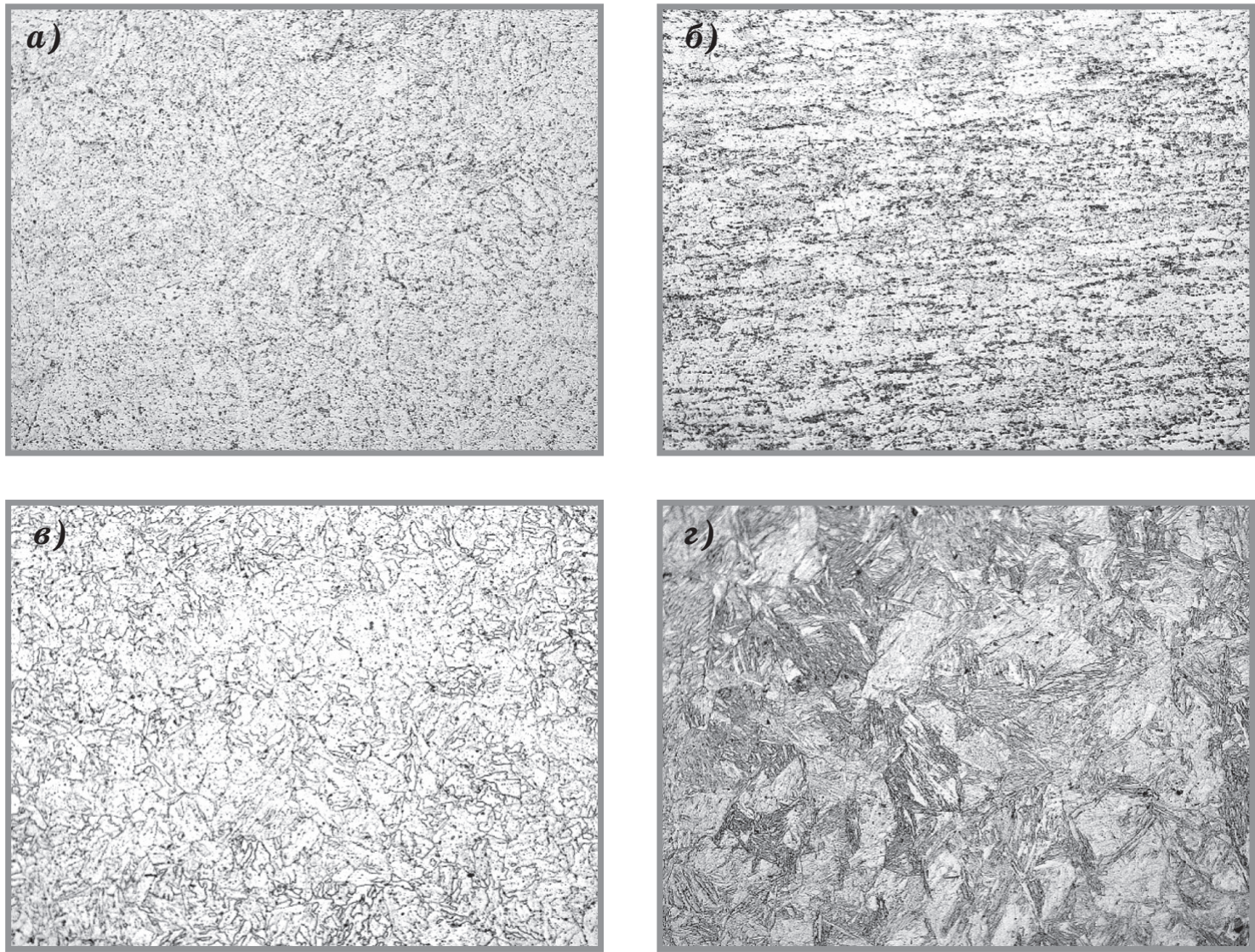

Рис. 5. Микроструктура образца, полученного сваркой трением:

a - микроструктура металла трубной решетки (х 500); б - микроструктура металла трубы (х 500); в - микроструктура металла ввариваемой детали (х 500); г - микроструктура металла сварного шва после травления в спиртовом растворе $15 \%$ азотной кислоты (х 500) 
- микроструктура металла 3ТВ со стороны трубной решетки и ввариваемой детали представляет собой сорбитообразную структуру, состоящую из феррита и карбидов, расположенных равномерно по границам и телу ферритных зерен;

- микроструктура металла ЗТВ со стороны трубы состоит из мелкоигольчатого мартенсита и глобулярных карбидов, наличие которых свидетельствует о перегреве металла трубы при сварке.

Для данного вида сварки характерно большое различие в микроструктуре по сечению образца. Это может способствовать возникновению электрохимической неоднородности между отдельными зонами изделия. В случае контакта изделий с агрессивными электролитами могут возникнуть микрогальванические элементы, которые способствуют ускорению коррозионных процессов. Как показывает практика, разрушение сварных конструкций в таких случаях происходит, как правило, по сварному шву или зоне термического влияния (3ТВ).

В электрохимическом отношении сварное соединение представляет собой сложную многоэлектродную систему, состоящую в основном из шва, зоны термического влияния и основного металла, между которыми возможны различные соотношения электродных потенциалов. [7]. Определение значений электродных потенциалов позволяет судить о коррозионной стойкости зон сварного соединения, установить наиболее уязвимые участки. Измерением электродных потенциалов можно воспользоваться для выбора наиболее безопасного в коррозионном отношении метода и режима сварки.

Наиболее благоприятным распределением потенциалов является случай равенства электродных потенциалов шва и основного металла $\left(\varphi_{\text {ш }}=\varphi_{\text {о.м. }}\right)$, когда будет идти процесс общей равномерной коррозии. В реальных условиях производства сварных конструкций добиться подобного равенства довольно сложно, поэтому предпочтительным является смещение электродного потенциала сварного шва в сторону более положительных значений, когда анодное растворение переносится на основной металл с одновременным снижением скорости коррозии шва $\left(\varphi_{\text {ш }}>\varphi_{\text {о.м. }}\right)$.

В связи с неравномерным характером коррозии сварного соединения массовый показатель не характеризует его коррозионную стойкость. Поэтому для оценки коррозионной стойкости сварных образцов был использован метод измерения электродных потенциалов. 
Результаты исследований приведены на рис 6.

Исследования электродных потенциалов зон сварного соединения проводили в соответствии с общепринятой методикой [7]. Электрохимические измерения заключались в регистрации электродных потенциалов характерных зон сварного соединения и основного металла специальным электрохимическим щупом. Значение электродного потенциала регистрировали вольтметром с погрешностью измерений $\pm 5 \%$.

Из рис. 6 а следует, что сварной шов, выполненный ручной дуговой сваркой, имеет потенциал минус 0,31 В (ХСЭ) и является более благородным по отношению к металлу как трубы, так и трубной решетки.
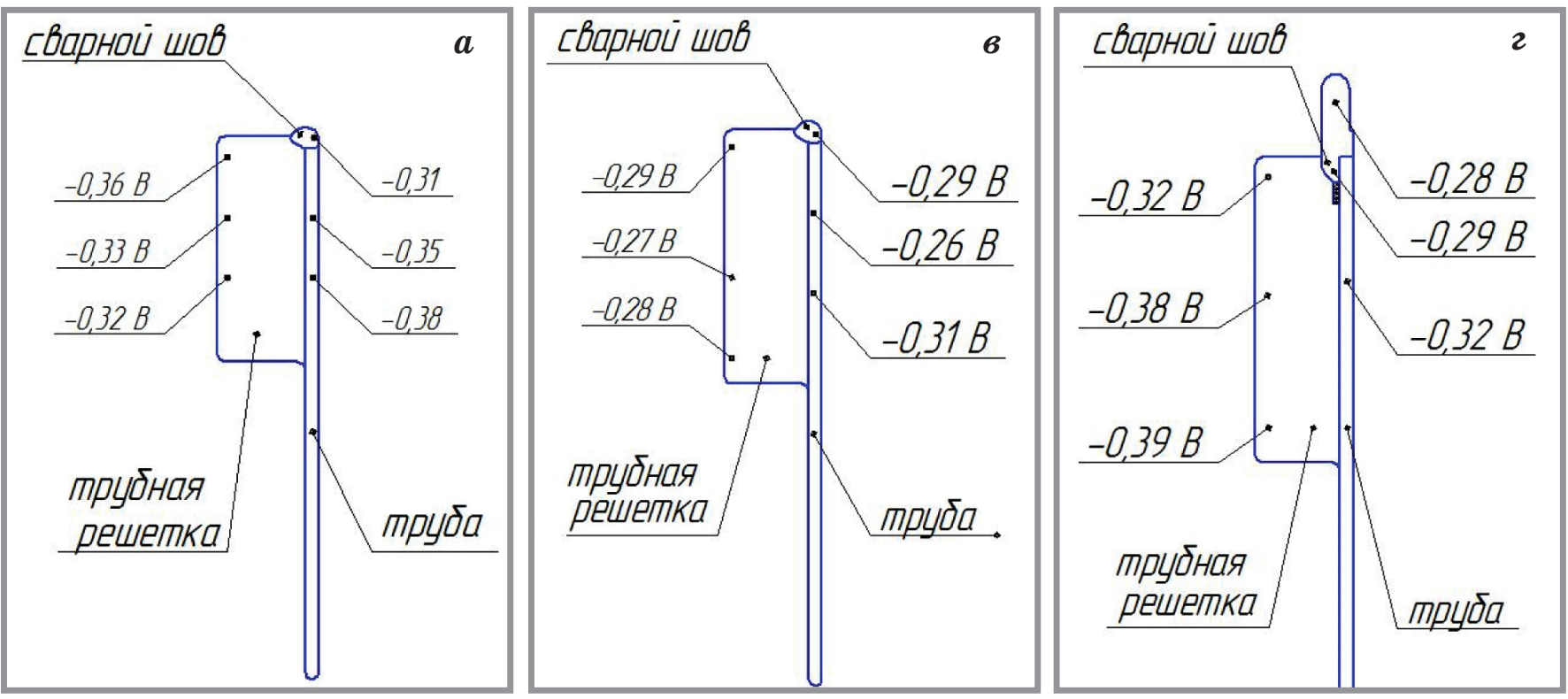

Рuc. 6. Схема точек замера и результаты измерения потенциалов образцов: а - РДС; б - РАД; в - сваркой трением

Результаты измерения потенциалов образца, полученного ручной аргонно-дуговой сваркой (рис. 6 б), показали, что потенциал шва практически одинаков с потенциалами трубы и трубной решетки, что объясняется действием окончательной термической обработки.

Для образца, полученного сваркой трением (рис. 6 в), видно, что потенциал сварного шва и ввариваемой детали равен или более положителен, чем потенциалы металла трубы и втулки. 
Таким образом, с точки зрения электрохимической коррозии изделия, получаемые сваркой трением, не уступают коррозионной стойкости изделиям, полученным дуговыми методами сварки.

С учетом имеющихся достоинств и особенностей применения сварки трением очевидно, что данный факт позволяет в дальнейшем рассматривать технологию сварки трением данных типов сталей как альтернативную дуговым способам.

\section{Выводы:}

- применение сварки трением для изготовления узла «труба - трубная решетка» теплообменных аппаратов из стали $15 \mathrm{X} 5 \mathrm{M}$ принципиально возможно, в т.ч. за счет изменения конструкции узла, и позволяет без применения термических операций получить неразъемные соединения труб с трубной решеткой, которые характеризуются высокими прочностными и пластическими свойствами;

- сварное соединение узла «труба - трубная решетка», полученное сваркой трением, характеризуется неоднородностью микроструктуры металла шва и зоны термомеханического влияния;

- сварное соединение узла «труба - трубная решетка», полученное сваркой трением без применения термических операций, обладает равномерным распределением электродных потенциалов характерных зон сварного соединения и основного металла, что свидетельствует о том, что в процессе эксплуатации в коррозионных средах скорость коррозии основного металла и металла сварного соединения будет одинаковой. 


\section{Библиографический список:}

1. Муликов Д.Ш., Ризванов Р.Г., Каретников Д.В., Файрушин А.М. Оценка возможности применения сварки трением для изготовления теплообменного оборудования из стали 15Х5М / Сварочное производство. - 2016. - № 3. - С. 47-51.

2. Каретников Д.В., Ризванов Р.Г., Муликов Д.Ш., Баландина А.Г., Файрушин A.M. Способ соединения узла «труба - трубная решетка» сваркой трением // Патент РФ № 2524468. МПК51 В 23 К 20/12, В 23 К 31/02. - заявитель и патентообладатель Уфа: УГНТУ. - 2012149757/02. - заявл. 21.11.2012; опубл. 27.07.2014, Бюл. № 21. - 6 с.

3. Ризванов Р.Г., Каретников Д.В., Файрушин А.М., Муликов Д.Ш. О возможности применения сварки трением для изготовления сварных трубных пучков из стали 15Х5М // Донецкий национальный технический университет «Прогрессивные технологии и системы машиностроения». - 2014. - № 4 (50). - С. 168-173.

4. Ткаченко Г.П., Бриф В.М. Изготовление и ремонт кожухотрубчатой теплообменной аппаратуры. - М.: Машиностроение, 1980. - 160 с.

5. Тукаев Р.Ф., Ибрагилов И.Г., Файрушин А.М., Сисанбаев А.В. Сравнительный анализ сварных швов в узле «труба - трубная решетка» кожухотрубчатого теплообменного аппарата из жаропрочной стали $15 \mathrm{X} 5 \mathrm{M}$, полученных различными способами сварки // Нефтегазовое дело. - 2013. - № 5. - С. 363-375.

6. Халилов А.А., Жаринова Н.В., Халимов А.Г., Файрушин А.М. Обеспечение технологической прочности сварных соединений из мартенситных хромистых сталей типа 15X5M / Нефтегазовое дело. - 2012. - Том 10, № 3. - С. 102-108.

7. Черепашкин С.Е., Латыпов О.Р., Кравцов В.В. Методы коррозионных исследований: учеб. пособие. - Уфа: РИЦ УГНТУ, 2014. - 86 с.

8. Salakhov T.R., Yamaliev V.U., Dubinsky V. A field-proven methodology for realtime drill bit condition assessment and drilling performance optimization [A fieldproven methodology for real-time drill bit condition assessment and drilling performance optimization]. In Proc. of SPE Russian Oil and Gas Technical Conference and Exhibition. 2008, pp. 281-288. (In Russian).

9. Ибрагилов И.Г., Ялилев М.З., Файрушин А.М., Саллин А.Н. Совершенствование технологии выполнения сварного узла «труба - трубная решетка» кожухотрубчатых теплообменных аппаратов, изготовленных из мартенситных сталей / Н Нефтегазовое дело. - 2009. - Т. 7, № 1. - С. 194-197.

10. Ялилев М.З. Совершенствование технологии изготовления узла «труба - трубная решетка» кожухотрубчатого теплообменного аппарата из жаропрочной стали 15Х5М: дисс. ... канд. техн. наук. - Уфа, 2011. - 108 с. 
11. Халилов А.Г., Бакиев А.В. Разработка технологии механизированной сварки в среде защитных газов сталей типа $15 \mathrm{X} 5 \mathrm{M}$ // Сборник материалов конференции РИЦ УГНТУ. - Уфа, 1998. - С. 51-52.

12. Лащинский А.А., Толчинский А.Р. Основы конструирования и расчета химической аппаратуры: справочник. - М.: АльянС, 2008. - 752 с.

13. Зайнуллин Р.С. Ресурсосберегающие технологии в нефтехимическом аппаратостроении. - Уфа: ТРАНСТЭК, 2000. - 348 с.

14. Халилов А.Г., Зайнуллин Р.С., Халилов А.А. Техническая диагностика и оценка ресурса аппаратов. - Уфа: УГНТУ, 2001. - 408 с.

15. Бакиев А.В. Технология аппаратостроения. - Уфа: УГНТУ, 1995. - 297 с.

16. Тукаев Р.Ф., Файрушин А.М., Сисанбаев А.В., Кучуков Т.М. Совершенствование технологии изготовления узла «труба - трубная решетка» кожухотрубчатого теплообменного аппарата из стали 15Х5М применением лазерной сварки // Сборник трудов СПбГПУ. - 2013. - № 3. - С. 1179-1185.

17. Муликов Д.Ш., Каретников Д.В., Ризванов Р.Г., Файрушин А.М. Модернизация конструкции узла крепления труб к трубным решеткам кожухотрубчатых теплообменных аппаратов из стали 15X5M // Нефтегазовое дело. - 2015. № 5. - С. 398-410.

18. Берлинер Ю.И., Бриф В.М. Анализ применимости современных методов крепления труб к трубным решеткам // Высокопроизводительные методы сварки в хим. и нефт. машиностроении. - 1970. - № 3. - С. 3-12;

19. Корольков П.М., Ханапетов М.В. Современные методы термической обработки сварных соединений. - М.: Высш. шк., 1987. - 112 с.

20. Вилль В.И. Сварка металлов трением. - М.: Машиностроение, 1970. - 176 с.

21. Лукин В.И., Ковальчук В.Г., Салоруков М.Л., Гриднев Ю.М., Жегина И.П. Исследование влияния параметров сварки трением и термической обработки на качество сварных соединений жаропрочных деформируемых никелевых сплавов / С Сарочное производство. - 2011. - № 4. - С. 26-30.

22. Халимов А.А., Жаринова Н.В., Халимов А.Г., Файрушин А.М. Обеспечение технологической прочности сварных соединений из мартенситных хромистых сталей типа 15Х5М // Нефтегазовое дело. - 2012. - № 3. - С. 102-108.

23. Иванов Л.А., Мулинова С.Р. Нанотехнологии и наноматериалы: обзор новых изобретений. Часть 1 // Нанотехнологии в строительстве. - 2017. - Том. 9, № $1 .-$ С. $88-106$.

24. Иванов Л.А., Мулинова С.Р. Новые технические решения в области нанотехнологий. Часть 1 // Нанотехнологии в строительстве. - 2016. - Том. 8, № 2. C. $52-70$. 
УВАЖАЕМЫЕ КОЛЛЕГИ!

ПРИ ИСПОЛЬЗОВАНИИ МАТЕРИАЛА ДАННОЙ СТАТЬИ

ПРОСИМ ДЕЛАТЬ БИБЛИОГРАФИЧЕСКУЮ ССЫЛКУ НА НЕЁ:

Ризванов Р.Г., Муликов Д.Ш., Каретников Д.В., Черепашкин С.Е., Ширгазина Р.Ф. Коррозионная стойкость сварного соединения узла «труба - трубная решетка», полученного сваркой трением // Нанотехнологии в строительстве. 2017. - Tом 9, № 4. - C. 97-115. - DOI: dx.doi.org/10.15828/2075-8545-20179-4-97-115.

\section{Dear Colleagues!}

THE REFERENCE TO THIS PAPER HAS THE FOLLOWING CITATION FORMAT:

Rizvanov R.G., Mulikov D.Sh., Karetnikov D.V., Cherepashkin S.E., Shirgazina R.F. Corrosion resistance of «tube - tubesheet» weld joint obtained by friction welding. Nanotehnologii v stroitel'stve $=$ Nanotechnologies in Construction. 2017, Vol. 9, no. 4, pp. 97-115. DOI: dx.doi.org/10.15828/2075-8545-2017-94-97-115. (In Russian). 